\title{
Evaluation of a clinical implementation of a respiratory muscle training group during spinal cord injury rehabilitation
}

\author{
Anja M. Raab ${ }^{1} \cdot$ Jörg Krebs ${ }^{1} \cdot$ Claudio Perret $^{2} \cdot$ Mirjam Pfister $^{1,2,3} \cdot$ Maria Hopman $^{4} \cdot$ Gabi Mueller $^{1}$
}

Received: 23 November 2017 / Revised: 19 March 2018 / Accepted: 19 March 2018

(C) International Spinal Cord Society 2018

\begin{abstract}
Study design Retrospective cohort study.

Objective To evaluate the clinical implementation of a respiratory muscle training group during rehabilitation of individuals with spinal cord injury.

Setting Spinal cord injury rehabilitation center.

Methods Individuals with complete or incomplete lesions during inpatient rehabilitation, level C4-T12.

Ten or more training sessions of either an inspiratory or a combined in- and expiratory muscle training were performed in a group setting with respiratory function measurements before and after the training period.

Results Analysis of 79 persons. Inspiratory muscle training was performed for 7 weeks with a median of 3.1 training sessions per week. Median training intensity was at $33 \%$ of baseline $\mathrm{PI}_{\max }$ and 58 repetitions were performed per training session. Respiratory mucle strength parameters improved by $18-68 \%$ of baseline values and lung function parameters by $11-31 \%$ after inspiratory muscle training.

The combined respiratory muscle training was performed for 13 weeks with a median of 2.8 sessions per week and 88 repetitions per training session. Median inspiratory training resistance was at $39 \%$ of baseline $\mathrm{PI}_{\max }$ and median expiratory training resistance was at $27 \%$ of baseline $\mathrm{PE}_{\max }$. Respiratory muscle strength parameters improved by $14-51 \%$ of baseline values and lung function parameters improved by $15-34 \%$ after the combined in- and expiratory muscle training.

Conclusion Respiratory resistance training improved respiratory function of individuals with acute spinal cord injury. Even if the combined respiratory muscle training was performed with more repetitions per training and nearly twice as long, relative improvements of respiratory function parameters were comparable with isolated inspiratory muscle training.
\end{abstract}

Notation of prior abstract publication/presentation: dmgp-congress in Hamburg, 26th-28th May 2016, Germany; Anja Raab and ISCoScongress in Vienna, 14th-16th September 2016, Austria; Anja Raab.

Anja M. Raab

anja.raab@paraplegie.ch

1 Clinical Trial Unit, Swiss Paraplegic Centre, Nottwil, Switzerland

2 Institute of Sports Medicine, Swiss Paraplegic Centre, Nottwil, Switzerland

3 Department of Health Sciences and Technology, Institute of Human Movement Sciences and Sport, ETH Zurich, Zurich, Switzerland

4 Department of Physiology, Radboud University Nijmegen, Nijmegen, The Netherlands

\section{Introduction}

After a spinal cord injury (SCI), respiratory function is impaired and the degree of impairment depends upon the lesion level [1]. Due to the complete or partial paralysis of the respiratory muscles, the effectiveness of coughing is reduced and the clearance of airway secretions is insufficient $[2,3]$. This retention of secretions may increase the airway resistance [4] and may cause respiratory complications such as atelectasis or pneumonia [2,5]. As a result of high airway resistance, respiratory work increases and may cause respiratory failure and subsequent complications in SCI individuals [6]. Respiratory complications are still among the leading causes of death in individuals with complete SCI [7] with only a slight decrease in mortality over the past 40 years [8]. In chronic SCI, a progressive decrease of respiratory function has been reported [6]. This observed decline in respiratory function exceeds the normal 
age-related decline [9]. The weakness of respiratory muscles and the inefficiency of breathing predispose individuals with tetraplegia to fatigue of the respiratory muscles $[10$, 11]. In able-bodied individuals, it has been demonstrated that, like other skeletal muscles, the respiratory muscles can be trained for both strength and endurance [12, 13]. In clinical practice, two main types of respiratory muscle strength training programs have been established, namely inspiratory and expiratory muscle strength training [13]. The degree and severity of respiratory muscle paralysis caused by SCI is usually decisive in choosing either an inor an expiratory training program or a combination of both [13].

Individual respiratory muscle training may be a central aspect of maintaining health and quality of life in this group of individuals with SCI. Additionally, respiratory function improves during inpatient rehabilitation due to spontaneous recovery [4, 14-16]. However, it has not yet been established, whether and to what extent the spontaneous recovery of respiratory function can be increased by specific respiratory muscle strength training. A statistically significant effect of respiratory muscle training on lung volume as well as on in- and expiratory muscle strength has recently been demonstrated for individuals with cervical SCI [3]. Unfortunately, no specific analyses regarding the efficacy of in- or expiratory muscle training or even a combination of both have been performed. However in the clinical routine, the question about the more effective training regime is often raised.

The purpose of this project was to evaluate the clinical implementation of a respiratory muscle training group during initial rehabilitation of individuals with SCI. Our main hypothesis was that significant differences in the respiratory muscle strength and lung volume can be reached by different respiratory muscle training regimes.

\section{Methods}

\section{Design and setting}

A retrospective cohort study was performed in a single SCI rehabilitation center. The study had been approved by the ethics committee. We certify that all applicable institutional and governmental regulations concerning the ethical use of data of human volunteers were followed during the course of this research.

\section{Study population}

Male and female inpatients with a primary diagnosis of traumatic or non-traumatic SCI, American Spinal Injury Association Impairment Scale (AIS) A-D, lesion level between $\mathrm{C} 4-\mathrm{T} 12$, aged 18 years or older who had participated in the respiratory muscle training group of the clinic from October 2010 to August 2015 and who had completed a minimum of 10 training sessions were included.

Persons with progressive neurological diseases such as multiple sclerosis or amyotrophic lateral sclerosis were excluded as well as persons with time post injury $\geq 1$ year, tracheostomy, mental disorders, acute or progressive respiratory diseases, bronchodilators or any other medication that could have influenced respiratory function at the time of assessment.

\section{Respiratory training and measurements}

\section{Respiratory training}

The respiratory muscle training group is part of our clinical routine since 2010 . The individuals performed the respiratory muscle training in a sitting position in their own wheelchair or on a chair (persons with the ability to walk). Up to five training sessions per week were performed in the group setting, supervised by a physiotherapist. The repetitions per training were defined individually with a target of 80-90 repetitions. After each training session, the training resistance and count of training repetitions were recorded for each person. The "Borg Rating of Perceived Exertion" (RPE) was used to document the person's self-rated exertion during each training session. The exertion is rated on a scale of 6-20, where 6 represents "no exertion at all" and 20 "maximal exertion". Four different training devices (IMT $^{\circledR}$, PEP ${ }^{\circledR}$, Powerlung BreatheAir ${ }^{\circledR}$, and Powerlung Trainer ${ }^{\circledR}$ ) were used for the training. The training device for isolated inspiration (Threshold IMT ${ }^{\circledR}$, Philips Respironics, USA) is a small handheld device, which includes a mouthpiece and a spring-loaded valve. The valve provides a constant inspiratory pressure training load, and the persons must generate a sufficiently negative pressure in order to open the inspiratory valve and inhale air. The valve is calibrated and can be adjusted $\left(9-41 \mathrm{cmH}_{2} \mathrm{O}\right)$ according to the individuals maximal inspiratory pressure $\left(\mathrm{PI}_{\max }\right)$. The training device for expiration (Threshold $\mathrm{PEP}^{\circledR}$, Philips Respironics, USA) has the identical principle as the IMT $^{\circledR}$. The difference is that the persons must generate a positive pressure $\left(5-20 \mathrm{cmH}_{2} \mathrm{O}\right)$ in order to open the expiratory valve and exhale air. The Powerlung BreatheAir ${ }^{\circledR}$ (PowerLung, Inc., Houston, TX, USA) is a small handheld device with a mouthpiece and two control dials with which the inspiratory and the expiratory resistance can be adjusted independently. The Powerlung Trainer ${ }^{\circledR}$ (PowerLung, Inc., Houston, TX, USA) has the same principle but offers slightly higher levels of resistance. Therefore, the individuals who were using the Powerlung ${ }^{\circledR}$ devices did in- and expiratory muscle training together, with an inspiratory 
resistance during inspiration and an expiratory resistance during expiration.

The respiratory muscle training was planned to start with the device set at $80 \%$ of the assessed $\mathrm{PI}_{\max }$ and maximal expiratory pressure $\left(\mathrm{PE}_{\max }\right)$ at best. Once a person was able to perform the training session with less effort (RPE) than the session before, the resistance was increased by the responsible physiotherapist.

\section{Respiratory function measurements}

Measurements of lung function and respiratory muscle strength were performed as part of the clinical routine. Respiratory function measurements were performed before the start of the respiratory muscle training $(\mathrm{t} 1)$ and after the end of participation in the respiratory muscle training group (t2). Lung function parameters were measured according to the ATS/ERS guidelines [17]. The following parameters were measured by body plethysmography (Master Screen ${ }^{\circledR}$ Body, Viasys Healthcare GmbH, Hoechberg, Germany): forced vital capacity (FVC), forced expiratory volume in $1 \mathrm{~s}$ $\left(\mathrm{FEV}_{1}\right)$, and peak expiratory flow (PEF). Maximal inspiratory pressure and $\mathrm{PE}_{\max }$ were measured using a respiratory pressure meter (Micro RPM, Micro Medical, Hoechberg, Germany). For all respiratory function measurements, the individualss had to breathe through a mouthpiece while wearing a nose clip. Sniff nasal inspiratory pressure (SNIP), as a simple and reliable method of measuring diaphragmatic muscle strength, was additionally measured with a handheld meter (Micro RPM, Micro Medical, Hoechberg, Germany). Each lung function measurement was performed at least three times. The highest value of each parameter was used for analyses.

\section{Statistical analysis}

The data of a person were included for analysis if lung function measurements before (t1) and after participation in the respiratory muscle training group (t2) were available and if at least 10 respiratory resistance training sessions had been performed. The differences between the respiratory function values measured before and those after respiratory muscle training was calculated for each individual.

Two training types were analyzed: (1) inspiratory muscle training (2) combined in- and expiratory muscle training. Persons who were assigned to the inspiratory group performed the training only with the $\mathrm{IMT}^{\circledR}$ device and those who were assigned to the combined group trained with a combination of the $\mathrm{IMT}^{\circledR}$ or the $\mathrm{PEP}^{\circledR}$ device and one of the Powerlung $^{\circledR}$ devices. The data were further analyzed for individuals with motor complete lesions (AIS A/B) and with motor incomplete lesions (AIS C/D). Normal

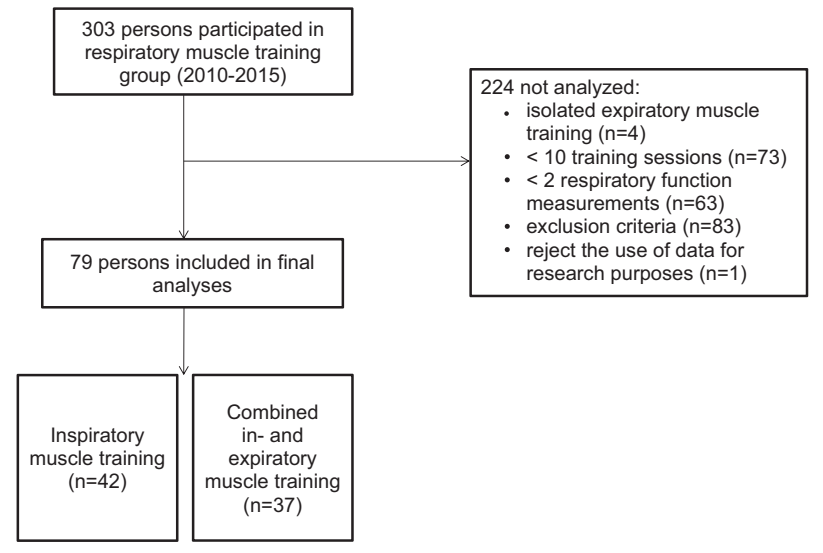

Fig. 1 Study flow diagram

distribution of the data was tested using QQ plots. Normal distributed data are presented as mean (standard deviation) and not normal distributed data as median (25 and $75 \%$ quartiles). Depending on the distribution of the data, paired $t$-tests or Mann-Whitney $U$ tests were used to compare the training-specific parameters (between-group differences) and paired $t$-tests or Wilcoxon tests were used to investigate differences in respiratory function between the $\mathrm{t} 1$ and $\mathrm{t} 2$ measurements (within-group differences). Statistical significance was set at alpha $\leq 0.05$. Benjamini Hochberg correction with a defined false-positive rate of $5 \%$ was used to adjust for multiple testing. All statistical analyses were performed using SPSS (Version 24.0, IBM, Somers, NY, USA).

\section{Results}

In total, 303 persons participated in the respiratory muscle training group. Overall, 224 individuals were excluded due to various reasons (Fig. 1). Thus, the data of 79 persons were analyzed (Fig. 1). The demographic data of the individuals are presented in Table 1, and their training-specific data are presented in Table 2.

\section{Inspiratory muscle training}

The respiratory function parameters before and after inspiratory muscle training are presented in Table 3 . The pre-post training differences in percent improvement from pre-training values of respiratory parameters in individuals with motor complete and incomplete lesions are presented in Figs. 2 and 3. The exertion during inspiratory training was classified as a mean of $13 \pm 1$ (maximum 20) on the RPE scale. The value 13 on the RPE scale is defined as "somewhat hard exercise, but it still feels OK to continue". 
Table 1 Characteristics of participants

\begin{tabular}{|c|c|c|c|c|}
\hline \multirow[t]{2}{*}{ Characteristics } & \multicolumn{2}{|c|}{ Inspiratory muscle training $(n=42)$} & \multicolumn{2}{|c|}{ Combined in- and expiratory muscle training $(n=37)$} \\
\hline & AIS A/B $(n=15)$ & AIS C/D $(n=27)$ & AIS A/B $(n=16)$ & AIS C/D $(n=21)$ \\
\hline Male/female $[n](\%)$ & $\begin{array}{l}10 / 5 \\
33.3 / 66.7\end{array}$ & $\begin{array}{l}22 / 5 \\
81.5 / 18.5\end{array}$ & $\begin{array}{l}14 / 2 \\
87.5 / 12.5\end{array}$ & $\begin{array}{l}18 / 3 \\
85.7 / 14.3\end{array}$ \\
\hline Age [years] & $48.0(30.0-58.0)$ & $63.0(37.0-73.0)$ & $44.5(30.0-52.5)$ & $60.0(41.0-72.5)$ \\
\hline $\begin{array}{l}\text { Time post injury } \\
\text { [years] }\end{array}$ & $0.2(0.1-0.3)$ & $0.1(0.1-0.2)$ & $0.1(0.1-0.2)$ & $0.2(0.1-0.2)$ \\
\hline Height $[\mathrm{cm}]$ & $\begin{array}{l}173.0 \\
(168.0-178.0)\end{array}$ & $\begin{array}{l}174.0 \\
(168.0-182.0)\end{array}$ & $176.5(172.0-184.8)$ & $174.0(170.0-181.0)$ \\
\hline Weight $[\mathrm{kg}]$ & $67.0(61.0-82.0)$ & $70.0(64.0-80.0)$ & $76.0(64.3-88.5)$ & $75.0(66.5-84.0)$ \\
\hline $\begin{array}{l}\text { Traumatic/non- } \\
\text { traumatic }[n](\%)\end{array}$ & $\begin{array}{l}13 / 2 \\
86.7 / 13.3\end{array}$ & $\begin{array}{l}21 / 6 \\
77.8 / 22.2\end{array}$ & $\begin{array}{l}15 / 1 \\
93.8 / 6.2\end{array}$ & $\begin{array}{l}15 / 6 \\
71.4 / 28.6\end{array}$ \\
\hline $\begin{array}{l}\text { Tetraplegia/paraplegia } \\
{[n](\%)}\end{array}$ & $\begin{array}{l}7 / 8 \\
46.7 / 53.3\end{array}$ & $\begin{array}{l}22 / 5 \\
81.5 / 18.5\end{array}$ & $\begin{array}{l}7 / 9 \\
43.8 / 56.2\end{array}$ & $\begin{array}{l}18 / 3 \\
85.7 / 14.3\end{array}$ \\
\hline
\end{tabular}

All data are reported as median (with $25 \%$ and $75 \%$ quartiles) unless indicated otherwise

AIS American Spinal Injury Association Impairment Scale, $A / B$ motor complete lesion, $C / D$ motor incomplete lesion

\section{Combined in- and expiratory muscle training}

The respiratory function parameters before and after combined in- and expiratory muscle training are presented in Table 4. The pre-post training differences in percent improvement from pre-training values of respiratory parameters in individuals with motor complete and incomplete lesions are presented in Figs. 2 and 3. The exertion during combined in- and expiratory training was classified as a mean of $14 \pm 1$.

\section{Discussion}

Both in- and combined in- and expiratory muscle training increased lung function and respiratory muscle strength on median by $27 \%$ (Figs. 1 and 2). An increase of about $30 \%$ (Fig. 2) in the respiratory muscle strength parameters after the inspiratory muscle training and in the lung function parameters of about $17 \%$ (Fig. 3) could be achieved. The combined in- and expiratory muscle training improved the respiratory muscle strength parameters on average by $34 \%$ (Fig. 2) and the lung function parameters by about $27 \%$ (Fig. 3). Even if the combined training regime was conducted with much higher training volumes (repetions per training session and number of weeks) compared to the inspiratory muscle training, relative improvements did not differ substantially between the two training regimes. On the other hand, relative training resistances (intensity) were quite similar in both training regimes.

\section{Respiratory muscle strength}

Generally, $\mathrm{PI}_{\max }$ as well as $\mathrm{PE}_{\max }$ were increased by both respiratory training regimes (Fig. 2) with a statistically significant improvement in $\mathrm{PI}_{\max }$ in individuals with motor complete and those with motor incomplete lesions (Tables 3 and 4). The principal intention of an expiratory muscle strength training is to boost the strength of the expiratory muscles [13] and the identical intention for the inspiratory muscle training and the inspiratory muscles. The greatest expansion after the respiratory resistance training is especially remarkable with $\mathrm{PE}_{\max }$ after the inspiratory muscle training in individuals with motor incomplete lesions (Fig. 2).

However, it is difficult to explain the differences in improvements between the four groups, since various influences as, e.g., differences in training volume, distribution of indivduals with para- and tetraplegia as well as spontaneous recovery may all have influenced the improvements and overlay isolated training effects. Interestingly, the SNIP values that mirror the force of the diaphragm and therefore should be stimulated mainly by inspiratory efforts, improved significantly after the combined in- and expiratory training in the motor complete and incomplete group, but not after isolated inspiratory muscle training (Table 4). Since the diaphragm contains more aerobic muscle fibers, probably the higher training volume in the combined training regime may have caused this difference. The $\mathrm{PI}_{\max }$ at baseline was greater than the $\mathrm{PE}_{\max }$ in all individuals regardless of the lesion group and the type of training, with the exception of individuals with motor incomplete lesions receiving combined training (Tables 3 
Table 2 Training-specific parameters

\begin{tabular}{llll}
\hline Characteristics & $\begin{array}{l}\text { Inspiratory muscle } \\
\text { training }(n=42)\end{array}$ & $\begin{array}{l}\text { Combined in- and expiratory } \\
\text { muscle training }(n=37)\end{array}$ \\
\hline Training sessions per week [Nr.] & $3.1(2.5-3.3)$ & $2.8(2.3-3.1)$ & $0.030^{\mathrm{a}}$ \\
Repetitions per training [Nr.] & $57.7(53.6-72.7)$ & $87.6(75.5-99.2)$ & $\leq 0.001^{\mathrm{a}}$ \\
Number of training weeks [Nr.] & $7.0(5.0-9.0)$ & $13.0(9.0-19.0)$ & $32.0(28.1-35.2)$ \\
Training resistance [cmH 20$] \%$ of & $26.5(21.8-33.0)$ & $38.8(13.1-57.7)$ & $0.001^{\mathrm{a}}$ \\
basis $\mathrm{PI}_{\max }$ value & $33.4(11.0-66.9)$ & $51.2(48.3-53.6)$ & 0.984 \\
$\begin{array}{l}\text { Training resistance }\left[\mathrm{cmH}_{2} 0\right] \% \text { of } \\
\text { basis } \mathrm{PE}_{\max } \text { value }\end{array}$ & n.a. & $26.7(2.5-68.7)$ & n.a. \\
\hline
\end{tabular}

All data are reported as median (with $25 \%$ and $75 \%$ quartiles)

AIS American Spinal Injury Association Impairment Scale, $A / B$ motor complete lesion, $C / D$ motor incomplete lesion, n.a. not applicable

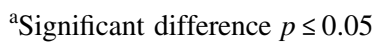

and 4). This is the logical consequence of the innervation of the respiratory muscles depending on the grade and level of lesion. Generally with higher lesion levels, the expiratory muscles are more impaired than the inspiratory muscles and therefore, inspiratory muscle strength is higher compared to expiratory muscle strength in individuals with SCI and particularly in those with tetraplegia $[6,18]$.

In any case, maximal respiratory pressure appears to be a more useful marker to detect weakness in respiratory muscles compared to lung volumes [19].

\section{Lung volumes}

We could demonstrate a statistically significant improvement in FVC of 14-34\% from baseline values in the motor complete as well as in the motor incomplete group, both after the isolated inspiratory as well as after the combined in- and expiratory muscle training (Fig. 3). Improvements in lung volumes after respiratory muscle strength training are apparently the consequences of higher in- and expiratory muscle strength since respiratory muscles are able to expand and compress the lungs to a higher extent which leads to increases in lung volumes. The FVC is defined as the total volume of air a person is able to exhale for the total duration of the test during maximal effort [20]. After a complete cervical lesion, individuals can only breathe with the movement of the diaphragm and accessory muscles around the neck. Therefore, individuals with tetraplegia reach much smaller values of FVC compared to paraplegics or ablebodied with a reduction of FVC to $30-50 \%$ of normal values [1]. Thus, the improvements in lung volumes found in this study are clinically relevant and may also justify the efforts to implement regular respiratory strength traning.

The FEV ${ }_{1}$ is the total volume of air that has been exhaled at the end of the first second of maximal forced expiration [20]. A recent Cochrane Review [3] identified no improvement in $\mathrm{FEV}_{1}$ after respiratory muscle training, however, our results show a statistically significant increase of $11-28 \%$ in $\mathrm{FEV}_{1}$ in all groups independent of the training regime (Fig. 3). This finding may be also important for secretions clearance, as $\mathrm{FEV}_{1}$ represents the ability to forcefully exhale air. Thus, a higher $\mathrm{FEV}_{1}$ and $\mathrm{FVC}$ seem to be protective against respiratory illness [21], and therefore respiratory muscle training should be an integral part of the clinical practice.

Furthermore, PEF, an even more important parameter for coughing [22], increased between 13 and 25\% (Fig. 3). For an effective cough, an $85-90 \%$ lung insufflation is required to achieve the maximum expiratory flow [2]. The inspiratory muscle weakness after an SCI restricts the pre-cough volumes and an effective cough for secretions clearance cannot be produced [2]. That is why our improvements in PEF after respiratory resistance training may also have a high clinical relevance for prevention of respiratory complications.

However, it has to be taken into account that improvements of 21 and 25\% in the motor complete group did not reach statistical significance. This can be explained by the very low sample size, since PEF has not been measured in all individuals of this groups (Tables 3 and 4).

\section{Training parameters}

Regarding training-specific parameters, our training duration was $\sim 15 \mathrm{~min}, 3$ days per week during 7-13 weeks (Table 2). These parameters lie in the middle of the reported values of a recent Cochrane review, which reported a daily training duration from 10 to $60 \mathrm{~min}, 3$ to 7 days per week for a period of 4 to 12 weeks [3]. Interestingly, training volume of the group who performed the combined in- and expiratory muscle training was much higher, i.e., more repetitions per training session and nearly twice of total training weeks, compared to the group who performed isolated inspiratory muscle training. Nevertheless, relative improvements compared to baseline values (Figs. 2 and 3) were quite comparable between the two groups. 
Table 3 Comparison of the respiratory function parameters pre- and post-inspiratory muscle training in individuals with motor complete SCI (AIS $\mathrm{A} / \mathrm{B})$ and motor incomplete SCI (AIS C/D)

\begin{tabular}{|c|c|c|c|c|c|c|}
\hline & \multicolumn{3}{|c|}{ Motor complete SCI (AIS A/B) } & \multicolumn{3}{|c|}{ Motor incomplete SCI (AIS C/D) } \\
\hline & $\begin{array}{l}\text { Respiratory function } \\
\text { parameters pre } \\
\text { training (t1) }\end{array}$ & $\begin{array}{l}\text { Respiratory function } \\
\text { parameters post } \\
\text { training (t2) }\end{array}$ & $p$ value & $\begin{array}{l}\text { Respiratory function } \\
\text { parameters pre } \\
\text { training (t1) }\end{array}$ & $\begin{array}{l}\text { Respiratory function } \\
\text { parameters post } \\
\text { training }(\mathrm{t} 2)\end{array}$ & $p$ value \\
\hline \multicolumn{7}{|l|}{$P I_{\max }$} \\
\hline $\begin{array}{l}\mathrm{A} / \mathrm{B}[n=12] \\
\mathrm{C} / \mathrm{D}[n=21]\end{array}$ & $63.0(36.5-72.0)$ & $80.0(49.5-93.5)$ & $0.008^{\mathrm{a}}$ & $48.0(33.3-59.8)$ & $64.5(51.8-80.5)$ & $\leq 0.001^{\mathrm{a}}$ \\
\hline \multicolumn{7}{|l|}{$P E_{\max }$} \\
\hline $\begin{array}{l}\mathrm{A} / \mathrm{B}[n=12] \\
\mathrm{C} / \mathrm{D}[n=21]\end{array}$ & $46.5 \pm 29.4$ & $51.4 \pm 28.3$ & 0.260 & $45.3 \pm 16.7$ & $64.5 \pm 27.0$ & $\leq 0.001^{\mathrm{a}}$ \\
\hline \multicolumn{7}{|l|}{ SNIP } \\
\hline $\begin{array}{l}\mathrm{A} / \mathrm{B}[n=12] \\
\mathrm{C} / \mathrm{D}[n=21]\end{array}$ & $46.7 \pm 18.4$ & $61.9 \pm 29.7$ & 0.227 & $44.6 \pm 19.7$ & $52.7 \pm 19.8$ & 0.076 \\
\hline \multicolumn{7}{|l|}{$F V C$} \\
\hline $\begin{array}{l}\mathrm{A} / \mathrm{B}[n=12] \\
\mathrm{C} / \mathrm{D}[n=22]\end{array}$ & $1.8 \pm 0.6$ & $2.1 \pm 0.6$ & $0.023^{\mathrm{a}}$ & $2.0 \pm 0.7$ & $2.3 \pm 0.6$ & $0.020^{\mathrm{a}}$ \\
\hline \multicolumn{7}{|l|}{$F E V_{l}$} \\
\hline $\begin{array}{l}\mathrm{A} / \mathrm{B}[n=12] \\
\mathrm{C} / \mathrm{D}[n=22]\end{array}$ & $1.5 \pm 0.5$ & $1.9 \pm 0.6$ & $0.008^{\mathrm{a}}$ & $1.7 \pm 0.6$ & $2.0 \pm 0.6$ & $0.002^{\mathrm{a}}$ \\
\hline \multicolumn{7}{|l|}{$P E F$} \\
\hline $\begin{array}{l}\mathrm{A} / \mathrm{B}[n=4] \\
\mathrm{C} / \mathrm{D}[n=14]\end{array}$ & $4.0 \pm 2.0$ & $5.3 \pm 1.7$ & 0.161 & $4.6 \pm 1.7$ & $5.2 \pm 1.5$ & $0.011^{\mathrm{a}}$ \\
\hline
\end{tabular}

All data are reported as mean \pm SD (for normal distributed data) or median (with $25 \%$ and $75 \%$ quartiles) for not normal distributed data $P I_{\max }$ maximal inspiratory pressure $\left(\mathrm{cmH}_{2} \mathrm{O}\right), P E_{\max }$ maximal expiratory pressure $\left(\mathrm{cmH}_{2} \mathrm{O}\right), S N I P$ sniff nasal inspiratory pressure $\left(\mathrm{cmH}_{2} \mathrm{O}\right), F V C$ forced vital capacity (L), $F E V_{l}$ forced expiratory volume in $1 \mathrm{~s}(\mathrm{~L}), P E F$ peak expiratory flow (L/s)

${ }^{a}$ Significant difference $p \leq 0.05$ (Benjamini Hochberg correction with a false-positive rate of 5\%)

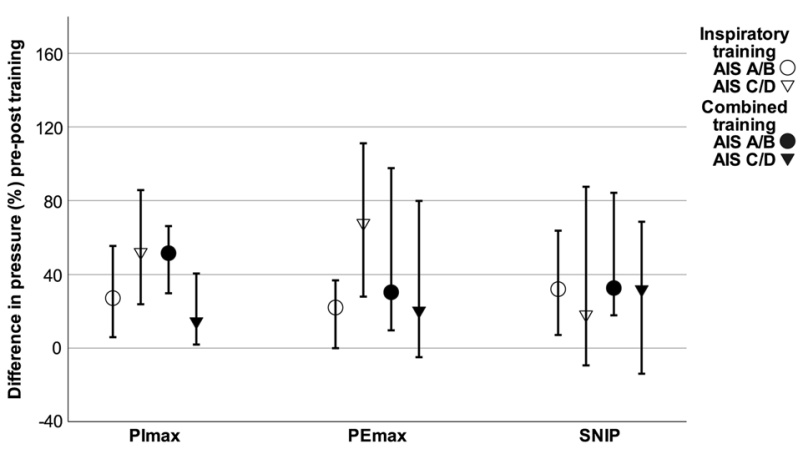

Fig. 2 The pre-post training differences in $\%$ (median $\pm 95 \%$ confidence intervall) of respiratory muscle strength parameters before and after the inspiratory and the combined in- and expiratory muscle training in individuals with motor complete (AIS A/B) and incomplete (AIS C/D) lesions. $\mathrm{PI}_{\max }$ maximal inspiratory pressure, $\mathrm{PE}_{\max }$ maximal expiratory pressure, SNIP sniff nasal inspiratory pressure

Considering relative training intensity, the two groups were comparable with an inspiratory training resistance of 33 and $39 \%$ of baseline $\mathrm{PI}_{\max }$, respectively (Table 2). This may create the hypothesis that training intensity may have a higher impact on improvements in respiratory function than

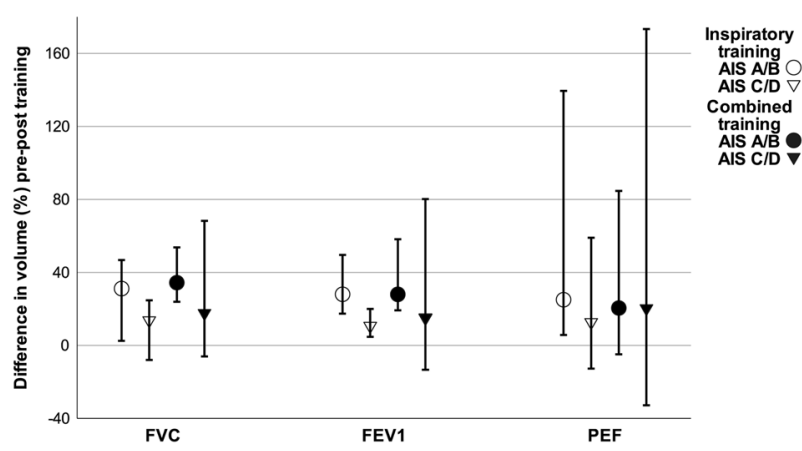

Fig. 3 The pre-post training differences in $\%$ (median $\pm 95 \%$ confidence interval) of respiratory lung function parameters before and after the inspiratory and the combined in- and expiratory muscle training in individuals with motor complete (AIS A/B) and incomplete (AIS C/D) lesions. FVC forced vital capacity, $\mathrm{FEV}_{1}$ forced expiratory volume in $1 \mathrm{~s}$, PEF peak expiratory flow

training volume. This should be addressed in a future study and may be of high clinical impact. Independent of our training stimuli which may have been below the optimal intensity [23], an improvement in respiratory function could be achieved, but on the other hand, we do not yet know how 
Table 4 Comparison of the respiratory function parameters pre- and post-combined in- and expiratory muscle training in individuals with motor complete SCI (AIS A/B) and motor incomplete SCI (AIS C/D)

\begin{tabular}{|c|c|c|c|c|c|c|}
\hline & \multicolumn{3}{|c|}{ Motor complete SCI (AIS A/B) } & \multicolumn{3}{|c|}{ Motor incomplete SCI (AIS C/D) } \\
\hline & $\begin{array}{l}\text { Respiratory function } \\
\text { parameters pre } \\
\text { training }(\mathrm{t} 1)\end{array}$ & $\begin{array}{l}\text { Respiratory function } \\
\text { parameters post } \\
\text { training ( } 2 \text { ) }\end{array}$ & $p$ value & $\begin{array}{l}\text { Respiratory function } \\
\text { parameters pre } \\
\text { training }(\mathrm{t} 1)\end{array}$ & $\begin{array}{l}\text { Respiratory function } \\
\text { parameters post } \\
\text { training }(\mathrm{t} 2)\end{array}$ & $p$ value \\
\hline \multicolumn{7}{|l|}{$P I_{\max }$} \\
\hline $\begin{array}{l}\mathrm{A} / \mathrm{B}[n=14] \\
\mathrm{C} / \mathrm{D}[n=17]\end{array}$ & $58.7 \pm 19.5$ & $89.8 \pm 28.2$ & $\leq 0.001^{\mathrm{a}}$ & $58.7 \pm 19.7$ & $75.6 \pm 21.3$ & $0.001^{\mathrm{a}}$ \\
\hline \multicolumn{7}{|l|}{$P E_{\max }$} \\
\hline $\begin{array}{l}\mathrm{A} / \mathrm{B}[n=14] \\
\mathrm{C} / \mathrm{D}[n=17]\end{array}$ & $46.5 \pm 22.1$ & $69.7 \pm 29.0$ & $0.001^{\mathrm{a}}$ & $69.5 \pm 31.6$ & $83.2 \pm 41.5$ & 0.091 \\
\hline \multicolumn{7}{|l|}{ SNIP } \\
\hline $\begin{array}{l}\mathrm{A} / \mathrm{B}[n=14] \\
\mathrm{C} / \mathrm{D}[n=17]\end{array}$ & $45.7 \pm 18.1$ & $68.5 \pm 19.5$ & $\leq 0.001^{\mathrm{a}}$ & $51.2 \pm 18.5$ & $65.2 \pm 24.1$ & $0.031^{\mathrm{a}}$ \\
\hline \multicolumn{7}{|l|}{$F V C$} \\
\hline $\begin{array}{l}\mathrm{A} / \mathrm{B}[n=15] \\
\mathrm{C} / \mathrm{D}[n=20]\end{array}$ & $2.1(1.8$ to 2.5$)$ & 2.7 (2.1 to 3.9$)$ & $0.001^{\mathrm{a}}$ & $2.4(2.0$ to 3.0$)$ & $3.5(2.4$ to 4.0$)$ & $0.011^{\mathrm{a}}$ \\
\hline \multicolumn{7}{|l|}{$F E V_{1}$} \\
\hline $\begin{array}{l}\mathrm{A} / \mathrm{B}[n=15] \\
\mathrm{C} / \mathrm{D}[n=19]\end{array}$ & $2.0(1.7$ to 2.3$)$ & $2.6(2.1$ to 3.4$)$ & $0.001^{\mathrm{a}}$ & $2.0(1.8$ to 2.3$)$ & $2.5(2.0$ to 3.3$)$ & $0.012^{\mathrm{a}}$ \\
\hline \multicolumn{7}{|l|}{$P E F$} \\
\hline $\begin{array}{l}\mathrm{A} / \mathrm{B}[n=5] \\
\mathrm{C} / \mathrm{D}[n=10]\end{array}$ & $4.5 \pm 1.8$ & $6.8 \pm 2.5$ & 0.136 & $4.7 \pm 1.4$ & $5.8 \pm 2.3$ & $0.040^{\mathrm{a}}$ \\
\hline
\end{tabular}

All data are reported as mean \pm SD (for normal distributed data) or median (with $25 \%$ and $75 \%$ quartiles) for not normal distributed data $P I_{\text {max }}$ maximal inspiratory pressure $\left(\mathrm{cmH}_{2} \mathrm{O}\right), P E_{\text {max }}$ maximal expiratory pressure $\left(\mathrm{cmH}_{2} \mathrm{O}\right), S N I P$ sniff nasal inspiratory pressure $\left(\mathrm{cmH}_{2} \mathrm{O}\right), F V C$ forced vital capacity (L), $F E V_{l}$ forced expiratory volume in $1 \mathrm{~s}(\mathrm{~L}), P E F$ peak expiratory flow $(\mathrm{L} / \mathrm{s})$

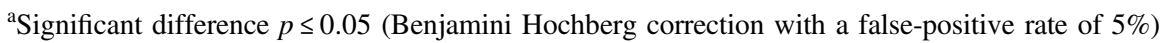

high the improvement could have been with higher training intensities.

\section{Limitations}

Respiratory muscle strength is affected by both in- and expiratory muscle training and therefore, there might have been an interaction of effects in the combined in- and expiratory muscle training group [24]. However, the evaluated data clearly demonstrated the positive effect of isolated inspiratory as well as combined in- and expiratory muscle training on respiratory function parameters in individuals with SCI.

Due to the retrospective analysis of a clinical implementation of respiratory muscle training, no control group was included and no systematic group allocation was performed.

Spontaneous improvement of the respiratory function parameters occurs [4, 14, 25, 26], however, the training effect on respiratory muscle strength is more pronounced [15]. The improvement in lung function in our study was similar to the magnitude reported for natural recovery, but lung function also depends on other factors (e.g., gender, age, and height) apart from respiratory muscle training. Respiratory muscle training mainly aims to improve respiratory muscle strength.

There is a preponderance of motor incomplete individuals with tetraplegia in our sample (Table 1), as a result of the higher proportion of incomplete individuals with tetraplegia in the SCI population [27]. This study mirrors the clinical situation without the potential influence of over-motivation generated by the participation in a study [28].

\section{Clinical relevance}

Independent of the training regime, from our point of view respiratory muscle training should be an integral part of the therapy. In order to assess and adapt the individual respiratory muscle training, repeated measurements of the respiratory function are needed. Recommendations for respiratory muscle training in hospital or community settings need to be developed and implemented in therapeutic practice. Furthermore, respiratory muscle training may be an useful way to reduce the rate of pneumonia due to the improvement of $\mathrm{PI}_{\max }$ [29]. 
In conclusion, respiratory muscle training revealed a great effect on improvements in respiratory function parameters and especially in respiratory muscle strength with improvements of up to $70 \%$ from baseline values. Even if the combined respiratory muscle training was performed with more repetitions per training and nearly twice as long, relative improvements of respiratory function parameters were comparable with isolated inspiratory muscle training. Therefore, future research should focus on the effects of training intensity.

The clinical implementation of a respiratory muscle training group during initial rehabilitation for individuals with SCI seems to be worthwhile.

Acknowledgements We thank the responsible physiotherapists of the Swiss Paraplegic Centre Nottwil for conducting and reporting the respiratory muscle training. The content of this publication was developed under grant from Wings for Life, grant number WFL-CH$017 / 14$.

\section{Compliance with ethical standards}

Conflict of interest The authors declare that they have no conflict of interest.

\section{References}

1. Chen CF, Lien IN, Wu MC. Respiratory function in patients with spinal cord injuries: effects of posture. Paraplegia. 1990;28:81-6.

2. Kang SW, Shin JC, Park CI, Moon JH, Rha DW, Cho DH. Relationship between inspiratory muscle strength and cough capacity in cervical spinal cord injured patients. Spinal Cord. 2006;44:242-8.

3. Berlowitz DJ, Tamplin J. Respiratory muscle training for cervical spinal cord injury. Cochrane Database Syst Rev. 2013;7: CD008507.

4. Brown R, DiMarco AF, Hoit JD, Garshick E. Respiratory dysfunction and management in spinal cord injury. Respir Care. 2006;51:853-68

5. Lanig IS, Peterson WP. The respiratory system in spinal cord injury. Phys Med Rehabil Clin N Am. 2000;11:29-43.

6. Alvisi V, Marangoni E, Zannoli S, Uneddu M, Uggento R, Farabegoli L, et al. Pulmonary function and expiratory flow limitation in acute cervical spinal cord injury. Arch Phys Med Rehabil. 2012;93:1950-6.

7. Schilero GJ, Radulovic M, Wecht JM, Spungen AM, Bauman WA, Lesser M. A center's experience: pulmonary function in spinal cord injury. Lung. 2014;192:339-46.

8. National Spinal Cord Injury Statistical Center. Spinal cord injury facts and figures at a glance. J Spinal Cord Med. 2015;38:812-3.

9. Postma K, Haisma JA, de Groot S, Hopman MT, Bergen MP, Stam HJ, et al. Changes in pulmonary function during the early years after inpatient rehabilitation in persons with spinal cord injury: a prospective cohort study. Arch Phys Med Rehabil. 2013;94:1540-6.
10. Manning H, McCool FD, Scharf SM, Garshick E, Brown R. Oxygen cost of resistive-loaded breathing in quadriplegia. J Appl Physiol. 1992;73:825-31.

11. Gross D, Ladd HW, Riley EJ, Macklem PT, Grassino A. The effect of training on strength and endurance of the diaphragm in quadriplegia. Am J Med. 1980;68:27-35.

12. Leith DE, Bradley M. Ventilatory muscle strength and endurance training. J Appl Physiol. 1976;41:508-16.

13. Sapienza CM, Wheeler K. Respiratory muscle strength training: functional outcomes versus plasticity. Semin Speech Lang. 2006;27:236-44.

14. Mueller G, de Groot S, van der Woude L, Hopman MT. Timecourses of lung function and respiratory muscle pressure generating capacity after spinal cord injury: a prospective cohort study. J Rehabil Med. 2008;40:269-76.

15. Liaw MY, Lin MC, Cheng PT, Wong MK, Tang FT. Resistive inspiratory muscle training: its effectiveness in patients with acute complete cervical cord injury. Arch Phys Med Rehabil. 2000;81:752-6.

16. Ledsome JR, Sharp JM. Pulmonary function in acute cervical cord injury. Am Rev Respir Dis. 1981;124:41-4.

17. Miller MR, Hankinson J, Brusasco V, Burgos F, Casaburi R, Coates A, et al. Standardisation of spirometry. Eur Respir J. 2005;26:319-38.

18. Laghi F, Tobin MJ. Disorders of the respiratory muscles. Am J Respir Crit Care Med. 2003;168:10-48.

19. Griggs RC, Donohoe KM, Utell MJ, Goldblatt D, Moxley RT 3rd. Evaluation of pulmonary function in neuromuscular disease. Arch Neurol. 1981;38:9-12.

20. Johnson JD, Theurer WM. A stepwise approach to the interpretation of pulmonary function tests. Am Fam Physician. 2014;89:359-66.

21. Stolzmann KL, Gagnon DR, Brown R, Tun CG, Garshick E. Risk factors for chest illness in chronic spinal cord injury: a prospective study. Am J Phys Med Rehabil. 2010;89:576-83.

22. Bach JR. Mechanical insufflation-exsufflation. Comparison of peak expiratory flows with manually assisted and unassisted coughing techniques. Chest. 1993;104:1553-62.

23. Mueller G, Hopman MT, Perret C. Comparison of respiratory muscle training methods in individuals with motor and sensory complete tetraplegia: a randomized controlled trial. J Rehabil Med. 2013;45:248-53.

24. Aarabi B, Harrop JS, Tator CH, Alexander M, Dettori JR, Grossman RG, et al. Predictors of pulmonary complications in blunt traumatic spinal cord injury. $J$ Neurosurg Spine. 2012;17:38-45.

25. Bluechardt MH, Wiens M, Thomas SG, Plyley MJ. Repeated measurements of pulmonary function following spinal cord injury. Paraplegia. 1992;30:768-74.

26. Axen K, Pineda H, Shunfenthal I, Haas F. Diaphragmatic function following cervical cord injury: neurally mediated improvement. Arch Phys Med Rehabil. 1985;66:219-22.

27. National Spinal Cord Injury Statistical Center (NSCISC), SCI facts and figures. J Spinal Cord Med. 2017;40:872-3.

28. McCambridge J, Kypri K, Elbourne D. Research participation effects: a skeleton in the methodological cupboard. J Clin Epidemiol. 2014;67:845-9.

29. Raab AM, Krebs J, Perret C, Michel F, Hopman MT, Mueller G. Maximum inspiratory pressure is a discriminator of pneumonia in individuals with spinal-cord injury. Respir Care. 2016;61:1636-43. 